\title{
Transvaginal Ultrasonographic Cervical Assessment as a Predictor Of Successful Labor Induction
}

By

Nahed H. Mohamed, Naglaa H. Mohamed and Mahmoud A. Mansour* Obstetrics and Gynecology Department, Faculty of Medicine for Girls, and

*Biochemistry Department, Faculty of Pharmacy

\section{Al- Azhar University}

\begin{abstract}
OBJECTIVE: To assess cervical maturation before labor induction with measurements obtained by transvaginal scans. Cervical length and detection rate of cervical gland area, were compared with Bishop score and serum Prostaglandin E2 levels at term for duration of labor, successful labor induction and mode of delivery.

STUDY DESIGN: Transvaginal scans were performed for detection of cervical gland area and measurements of cervical length in 80 singleton pregnant women scheduled for induction of labor at $\geq 37$ weeks of gestation. Cervical ripening was assessed simultaneously by Bishop score and preinduction serum prostaglandin E2 metabolite was detected by ELISA technique. Results were compared against parity, gestational age, and mode of delivery and induction-to-delivery interval.

RESULTS: Seventy percent of the studied women were delivered vaginally (46.7\% of nulliparous and $84 \%$ of multiparous women). Women with cervical length $<3.0 \mathrm{~cm}$ and also women with higher PGE2 levels had shorter labors $(\mathrm{P}<0.01)$ and were more likely to be delivered vaginally $(\mathrm{P}<0.05)$. Significant decrease in the detection rate of cervical gland area in women who had shorter labors and were delivery vaginally $(\mathrm{P}<0.05)$ and also in multiparous than nulliparous women $(\mathrm{P}<0.01)$. The mean serum PGE2 level was significantly higher in multiparous than nulliparous women $(\mathrm{P}<0.01)$. Women with Bishop score > 4 also had shorter labors and were more likely to be delivered vaginally $(\mathrm{P}<0.05)$. Whereas, there was no significant difference in the mode of delivery with Bishop score $\leq 4(\mathrm{P}>0.05)$. Cervical length, detection rate of cervical gland area serum PGE2 levels, and Bishop score showed linear correlation with duration of labor $(\mathrm{r}=0.47 \mathrm{P}<0.05, \mathrm{r}=0.58 \mathrm{P}<0.01, \mathrm{r}=0.67 \mathrm{P}<0.05$ and $\mathrm{r}=0.43, \mathrm{P}$ $<0.01$ respectively).
\end{abstract}

CONCLUSIONS: Ttransvaginal ultrasonographic cervical measurement is comparable to Bishop score in assessing cervical ripeness for labor induction. Cervical measurement parity and serum PGE2 were independent predictors of the mode of delivery. Whereas, the mode of delivery cold not be predicted in women with Bishop score $\leq 4$.

\section{Introduction}

Induction of labor in women with an unripe cervix at term remains a challenge for the obstetrician. It is one of the most common aspects of obstetric practice, with $15 \%$ of all pregnant women undergoing iinduction or augmentation of labor (Ventura et al, 1998). Prostaglandins undoubtly play an important role in the control of cervical ripening in human. Ellwood et al (1981) reported that the cervical production of prostaglandins increases at term followed by sharp increase at parturition and the amniotic fluid 
concentrations of $\mathrm{PGE}_{2}$ and $\mathrm{PGF}_{2}$ directly correlated to cervical ripening in human.

Assessment oof the cervix has been used as a predictor of the probability of vaginal delivery. Traditionally, the Bishop score has been used to assess the cervix. Transvaginal ultrasonographic (TVU) measurement could represent more accurate assessment of the cervix than digital examination because the supravaginal portion of the cervix usually comprises about 50\% of cervical length, but this is highly variable among individuals. This portion is difficult to assess digitally. In addition, effacement is subjective and can vary considerably among examiners. Moreover, effacement is difficult to determine in the closed cervix. In contrast, transvaginal ultrasonographic cervical measurement is quantitative and easily reproducible. Cervical shortening, as seen on sonograms, has been proposed as representative of the process of cervical effacement (Ware et al, 2000)

This study was designed of assess cervical ripening before labor induction via transvaginal ullrasonographic cervical length measurements and detection rate of cervical gland area, as predictors of successful labor induction. The ultrasonographic measurements were compared with Bishop score and serum prostaglandin E2 level, measured at term, for duration of labor and mode delivery.

\section{Patients and Methods}

This study recruited 80 pregnant women with singleton term gestations scheduled for induction of labor at $\geq 37$ weeks gestation. All were vertex presentation, selected from the attendants of the Obstetrics department at Al- Zahraa University Hospital during the period from January 2000- to August 2000. Parity, gestational age, and indication for induction, mode of delivery, induction agents, induction to delivery interval and cervical Bishop score were recorded. Women whose parity greater than two, with previous uterine scar or with history of prelabor rupture of membranes were excluded. According to the parity the study included two groups:

Group 1: thirty nulliparous women, and Group 11: fifty multiparous women.

Induction were medically indicated; the most common indications for induction included postdate pregnancies, mild preeclampsia and intrauterine growth restriction. Pregnant women with uncertain date, women with prior cesarean delivery or with obstetric indications of cesarean delivery were excluded.

All enrolled subjects underwent transvaginal ultrasonographic examination for measurement of cervical length and detection of the presence of endocervical mucosal layer. Blood samples were taken before induction of labor and another samples were taken for women that were not delivered six hours after induction. Cervical Bishop scores was recorded before induction of labor and after 8 hours or more for cervical assessment of those women with prolonged induction period.

Induction of labor was initiated within 6 hours of ullrasonographic examination. Routine maternal cares and antepartum fetal testing was underwent during induction. Stripping the membranes was preformed for some cases under aseptic conditions. Induction agents used were PGE2 vaginal tablets (3 $\mathrm{mg})$, amniotomy and / or oxytocin. For multiparous women, half PGE2 vaginal tablet was used. PGE2 vaginal tablet was placed in the posterior fornix and repeated 6-8 hours later if the cervix unripe (Bishop score 
< 5), for maximum 3 doses., until satisfactory cervical ripening or uterine activity is established. For labor enhancement, an infusion of 5IU oxytocin per $500 \mathrm{ml}$ saline was used.

Ultrasonographic measurements, Bishop score and PGE2 levels were compared for duration of labor and mode of delivery to detect whether of these tests could select women for whom successful induction of labor was predicted.

Transvaginal ultrasonographic measurement according to lams et al (1996) established technique. Cervical length and endocervical mucosal layer was measured with a transvaginal real time ultrasonographic probe with the standard sagital view of the cervix and endocervical canal identified while the patient's bladder was empty. Care was taken to avoid pressure on the cervix from the ultrasonography probe. The appropriate view for measurement was determined by finding the triangular echolucency at the external os, a Vshaped notch at the internal os, and a faint line of echodensity or echolucency between these markers. Pressure artifacts or undue pressure on the cervical canal, which might have artificially created the impression of a longer cervix, was avoided by withdrawing the probe until the image blurred and then reapplying only sufficient pressure to restore the image. Failing to appreciate that not all cervical canals follow a straight line can lead to underestimates of length. The width of the anterior and posterior cervical lips should appear equal on the image used, reflecting the fact that the cervical canal is normally central. The cervical length was measered as straight line from the proximal to distal point of apposition of the mucosal surface of the anterior and posterior cervix. The cervix was measured three times along the line made by the interface or the mucosal surfaces, and calipers were placed at the notches made by the internal os and external os. The cervical length measurement rrecorded was the "shortest" (not the average) best measurement that most clearly displayed the previously described criteria.

The endocervical canal typically appears as thin, central echogenic strip similar to the endometrial cavity echo. The presence of an endocervical mucosal layer or its disappearance was imaged. This mucosa represented cervical glands, which disappear during the process of cervical ripening as hypothesized by Sekiya et al (1998).

Measurement of maternal serum PGE2: Prostaglandin E2 metabolites (C-17 metabolite, 12 hydroxyheptadecatrienoic acid (HHT) + Malondialdehyde (MDA), were measured for the study groups 5 minutes before the procedure for induction, to detect the basal level and 6-hour after the procedure. It was measered at Biochemistry Department, Faculty of Pharmacy, Al- Azhar University. Prostaglandin E2 metabolites were measured by ELISA assay (Neogen Corporation). This is an Enzyme-Linked Immunosorbent Assay for the quantitative analysis of Prostaglandins E2 levels in biological fluid. This test kit operates on the basis of competition between the enzyme conjugate and the PGE2 in the sample for limited number of binding sites on the antibody coated plate. Quantitative test results may be obtained by measuring and comparing the absorbency reading of the wells of the samples against the standards with a microplate reader or spectrophotometer at $650 \mathrm{~nm}$. The extent of color development is inversely proportional to the amount of PGE2 in the sample or standard. For example, the absence of 
PGE2 in the sample will result in a bright blue color, whereas the presence of PGE2 will result in decreased or no color development.

Comparison between groups are assessed by one way analyses of variance ( Krustal - Wallis and MannWhitney test). Data were analyzed using student's $\mathrm{t}$ test and the $X^{2}$ test. The results are expressed as mean valves \pm SD. Correlation was determined by Spermans test. Statistical significance was determined at $\mathrm{P}<0.05$ and $\mathrm{P}<$ 0.01 .

\section{Results:}

The results of this study were recorded in five tables and two figures. Both nulliparous and multiparous women were matched for maternal age, gestational age at delivery, cervical length and Bishop scores (table 1). The choice of induction agent depends on the difference in cervical ripeness between the two groups. Whereas, most of multiparous women received oxytocin $(70 \%)$ for induction of labor, $60 \%$ of nulliparous women received prostaglandin E2 vaginal tablets. No maternal or fetal deaths occurred during the study.

Imaging of endocervical, mucosal layer by TVU for assessment of cervical ripeness showed significant decrease in the detection rate of cervical gland area in multiparous than nulliparous women $(\mathrm{P}<0.01)$ table 1 . We noticed that the disappearance of the endocervical, mucosal layer was coincide with cervical length less than $3 \mathrm{~cm}$.

Second blood samples for PGE2 measurements were taken only for 65 out of 80 studied women who had longer induction to delivery period $(>6$ hr). Serial serum PGE2 measurements revealed significantly higher mean concentrations with improvement of cervical ripening in women who had delivered vaginally. There was no statistical difference in mean PGE2 concentrations between multiparous than nulliparous women (table 2). In addition, there were significant decrease in serum PGE2 concentration in women who delivered by cesarean sections than those who delivered vaginally Table (3).

In the present study, cervical length of $3 \mathrm{~cm}$ used as cut off point. Significantly shorter duration of labor was noticed with higher PGE2 concentrations, decrease in the detection rate of cervical gland area, cervical length $<3 \mathrm{~cm}$ and Bishop score $>4(\mathrm{P}<$ 0.01 - table 3 and table 4).

With mode of delivery used as the primary outcome, women with decrease in the detection rate of cervical gland area and those with cervical length $<3$ $\mathrm{cm}$ were more likely to be delivered vaginally as were women with Bishop score $>4 \quad(p<0.05)$. The decision to perform cesarean deliveries were taken mainly for failure to archive satisfactory cervical ripening, failure of establishment of uterine activity or failure of progression of labor after an otherwise normal induction with a fully dilated cervix. Cesarean deliveries were also indicated because of uterine hyperstimulation in one case and due to signs of fetal distress during normal labor induction and normal frequency of contractions in two cases. There was no significant differences in the mode of delivery in women with Bishop score $\leq 4 \quad(\mathrm{P}>0.05)$. Whereas, there was significant decrease in the detection rate of cervical gland area in women who had shorter labors and were delivery vaginally $(\mathrm{P}<0.05)$ table 4 .

Cervical length, detection rate of cervical gland area, serum PGE2 levels, and Bishop score showed linear correlation with duration of labor $(\mathrm{r}$ $=0.47 \mathrm{P}<0.05, \mathrm{r}=0.58 \quad \mathrm{P}<0.01, \mathrm{r}=$ $0.67 \mathrm{P}<0.05$ and $\mathrm{r}=0.43, \mathrm{P}<0.01$ 
respectively) Table 5 .

Table (1) clinical characteresris of the studied women

\begin{tabular}{|c|c|c|c|}
\hline Items & $\begin{array}{l}\text { Nulliparous } \\
\text { ( group 1) }\end{array}$ & $\begin{array}{c}\text { Multiparous } \\
\text { (group 11) }\end{array}$ & $\mathrm{P}$ value \\
\hline $\begin{array}{l}\text { Number }(\%) \\
\text { Age (years)mean } \pm \mathrm{SD}(\text { range }) \\
\text { Mode of delivery }(\mathrm{N} \%) \text { : } \\
\text { vaginal delivery }(\mathrm{N}=56) \\
\text { cesarean section }(\mathrm{N}=24) \\
\text { GA at vaginal delivery: } \\
\text { At } 38-<39 \mathrm{wks} \\
\text { At } 39-<40 \mathrm{wks} \\
\text { At } 40-<41 \mathrm{wks} \\
\geq 41 \text { wks } \\
\text { Mean GA at delivery (weeks) } \\
\text { Initial Bishop score: mean }(\text { range }) \\
\text { Mean cervical length }(\mathrm{cm} \pm \mathrm{SD}(\mathrm{range}) \\
\text { Rate of cervical gland area : } \\
\text { presence }(\%) \\
\text { disappearance }(\%) \\
\text { Mean duration of labor }(\mathrm{hr})\end{array}$ & $\begin{array}{lc}30 & 37.5 \% \\
26.8 \pm 4.4 & (20-36) \\
14 & 46.7 \% \\
16 & 53.3 \% \\
& \\
4 & \\
5 & 13.3 \% \\
& 16.6 \% \\
6.6 \% & 1 \\
40 \pm 1.7 & \\
3 \pm 4 & (0-6) \\
3.0 \pm 0.7 & (0.5-4.5) \\
& \\
48.4 \% & \\
51.6 \% & \\
& \\
15.9 \pm 6.5 & \end{array}$ & $\begin{array}{lr}50 & 62.5 \% \\
26.6 \pm 4.8 & (21-38) \\
42 & 84 \% \\
8 & 16 \% \\
6 & 12 \% \\
12 & 24 \% \\
18 & 36 \% \\
& \\
12 \% & \\
40 \pm 1.7 & \\
4 \pm 3 & (2-8) \\
2.3 \pm 9 & (0.5-4.0) \\
30.1 \% & \\
69.9 \% & \\
9.5 \pm 7.6 & \end{array}$ & $\begin{array}{l}>0.05(\mathrm{NS}) \\
>0.05(\mathrm{NS}) \\
>0.05(\mathrm{NS}) \\
<0.01(\mathrm{~S}) \\
<0.05(\mathrm{~S})\end{array}$ \\
\hline
\end{tabular}

$$
\text { S = Significant }
$$

NS = Non Significant

Table (2) Serum PGE2 levels (mean $\pm \mathrm{SD}, \mathrm{ng} / \mathrm{ml}$ ) in the studied groups

\begin{tabular}{|l|l|l|l|}
\hline Serum PGE2 levels (ng/ml) & Nulliparous & Multiparous & P value \\
\hline Levels before induction & $4.7 \pm 1.3$ & $5.1 \pm 2.1$ & $<0.05(\mathrm{NS})$ \\
Levels 6 hours after induction ( N=65/80) & $10.4 \pm 6.8$ & $14.8 \pm 10.1$ & $<0.05(\mathrm{NS})$ \\
P values & $<0.05(\mathrm{~S})$ & $<0.05(\mathrm{~S})$ & \\
\hline
\end{tabular}

Table (3) Serum PGE 2 levels (mean $\pm \mathrm{SD}, \mathrm{ng} / \mathrm{ml}$ ) in relation to Gestational age at the time of delivery and duration of labor $(\mathrm{hr} \pm \mathrm{SD})$ in all the studied women

\begin{tabular}{|c|c|c|c|}
\hline & Number.of patients & $\begin{array}{c}\text { Serum PGE2 levels ng/ml } \\
\text { (2d sample) }\end{array}$ & $\begin{array}{l}\text { Induction-to- } \\
\text { delivery interval ( } \\
\text { hr) }\end{array}$ \\
\hline GA at vaginal delivery & 6 & $6.2 \pm 2.1$ & $15.2 \pm 1.06$ \\
38 week & 16 & $14.8 \pm 5.3$ & \pm 0.91 \\
39 week & 34 & $12.4 \pm 5.4$ & $13.1 \pm 4.34$ \\
\hline 40 week & 24 & $4.2 \pm 1.3$ & - \\
\hline Cesarean section & &
\end{tabular}


Table (4) Bishop score and cervical length in relation to duration of labor (mean \pm SD hour) and mode of delivery in the studied women as a whole

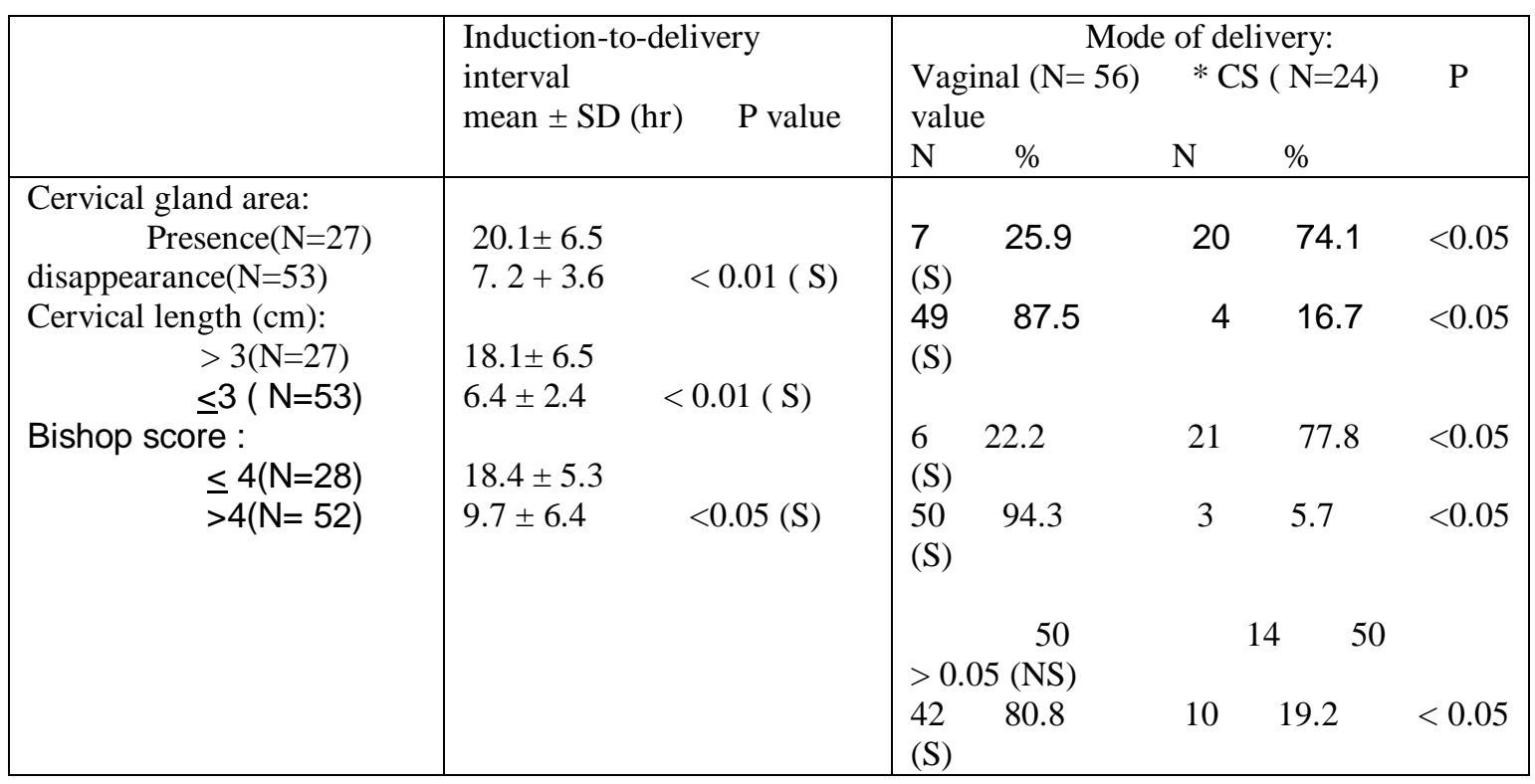

${ }^{*} \mathrm{CS}=$ cesarean section

Table (5) Correlation of cervical length, detection rate of cervical gland area, Bishop score, and PGE2 with Duration of labor

\begin{tabular}{|l|lc|}
\hline Items & \multicolumn{2}{|l|}{ Duration of labor } \\
& $\mathrm{r}$ & $\mathrm{P}$ \\
\hline Cervical length & 0.047 & $<0.05$ \\
Cervical gland area & 0.58 & $<0.01$ \\
Bishop score & 0.43 & $<0.01$ \\
Serum PGE2 & 0.67 & $<0.05$ \\
\hline
\end{tabular}




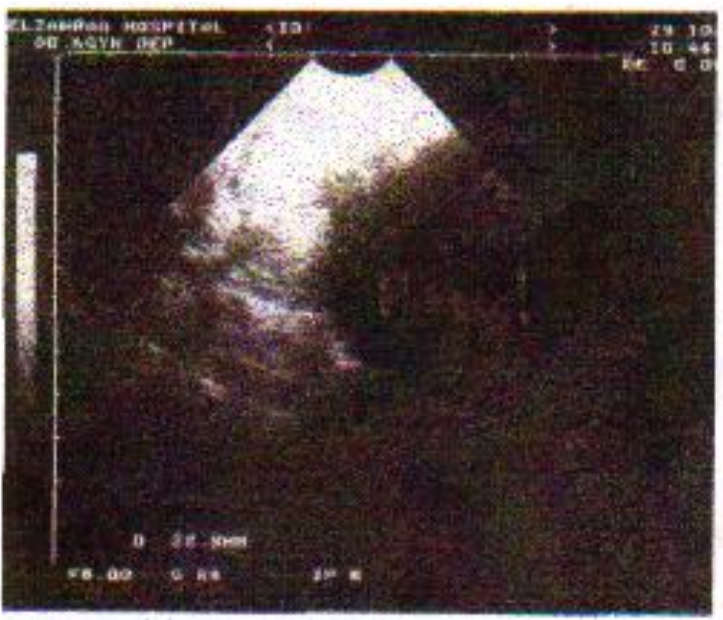

(a)

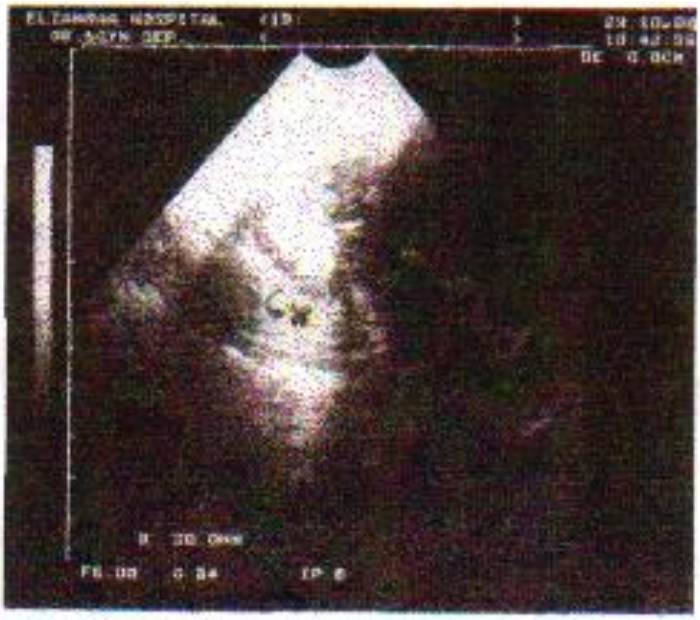

(b)

Figure (1) Transvaginal sagittal scan showing cervical canal and fetal head of two cases: (a) gestational age 39 weeks with cervical length (between the two marks) measuring $22 \mathrm{~mm}$ and visible cervical mucosa. By examination, cervical Bishop score was three. (b) Gestational age 41 weeks with cervical length measuring $30 \mathrm{~mm}$ and visible cervical mucosa. By examination cervical Bishop score was zero and the patient had delivered by cesarean section.

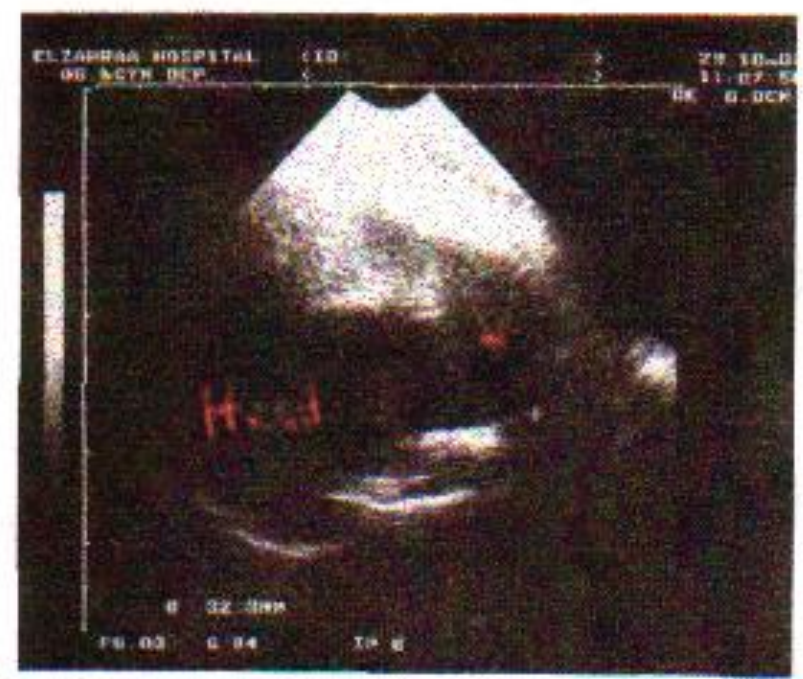

Figure (2)Transvaginal sagittal scan showing the cervix, fetal head and the bag of fore water (arrow) plugging through the cervical os ( between the two marks ) which was measured inner- inner $=32 \mathrm{~mm}$. The cervical canal $3 \mathrm{~mm}$.By examination cervical effacement was $80 \%$ and the cervical Bishop score was 8 and the patient had delivered vaginally within 6 hours from

\section{Discussion}

The present study showed that transvaginal measurem -ents, cervical length and detection of

cervical gland area were comparable to 
the Bishop score and serum PGE2 in assessing cervical ripeness for labor induction. There was positive correlation between TVU measurement of the cervix, Bishop score and serum PGE2 levels and duration of labor. Our results were in agreement with that of Khoury el al (1997) and Ware et al (2000). Khoury el al (1997) demonstrated that all women with cervical length $<3.0 \quad \mathrm{~cm}$ delivered vaginally and had a significantly shorter labor, in comparison with $73 \%$ of those with cervical length $>3.0 \mathrm{~cm}$.

In contrast, Paterson-Brown et al (1991) attempted to replace the traditional Bishop score for cervical assessment before labor induction with measurements obtained by transvaginal scan, cervical length. Unfortunately, most parameters showed no correlation with induction outcome. On the other hand, Gonen et al (1998) found that only the Bishop score and parity, not cervical length, significantly correlated with vaginal delivery and duration of labor.

Boozarjomehri et al (1994) found that the presence of cervical wedging on ultrasonography was a better predictor of duration of labor and found that cervical length correlated with duration of latent phase and not total duration. However, Munoz et al (1997) found that both cervical length and Bishop score showed a correlation with vaginal delivery, but only a cervical dilatation index (cervical length divided by anteroposterior diameter) was an independent predictor.

Sekiya et al (1998) studied the endocervical mucosa seen with transvaginal sonography. They hypothesized that this mucosa represented cervical glands, which disappear during the process of cervical ripening. They proposed that the detection rate of cervical gland area remained particularly constant until the 31st week of pregnancy, but significantly decrease thereafter. They found a strong correlation between the presence of an endocervical mucosal layer and a traditional Bishop score.

In the present study, cervical length, detection rate of cervical gland area, parity and PGE2 levels were found independent predictors of the mode of delivery, whereas the Bishop score was not. We found that $3-\mathrm{cm}$ cutoff point for cervical length was the best predictor of vagina delivery. These findings revealed the potential usefulness of the ultrasonographic technique in prediction of mode of delivery and duration of labor.

The use of delivery mode as an outcome variable obviously affects resulting conclusions because this parameter is influenced by a number of factors, such as birth weight, maternal stature, and indications for cesarean delivery. It is widely accepted that induction, particularly in the presence of an unripe cervix, increases the risk of cesarean delivery. The overall cesarean rate in our study appears high $(30 \%)$, particularly in light of the $53.3 \%$ rate among nulliparous women. That result was comparable to cesarean rate of Ware et al (2000) study. In contrast, Xenakis el al (1997) reported that 34\% of nulliparous women and $23 \%$ of multiparous women who had a Bishop score $<3$ and who underwent medically indicated induction had cesarean delivery; the overall cesarean rate was $20 \%$. In a study comparing hydroscopic dilators and prostaglandin $\mathrm{E}$ for induction of women with a Bishop score <9, Williams et al (1997) showed a $28 \%$ cesarean delivery rate. Although the range of Bishop scores in our patients and these studies were nearly similar, the induction agents were 
different. However, most reports have not shown a difference in the rate of cesarean delivery with different agents. Moreover, the percentage of cesarean deliveries in this study is higher than that reported in previous studies using misoprostol (Sanchez - Ramos et al 1997). There may be different characteristics of the patient population or institutional management protocols that should be considered between these studies and our study, and that may account for the higher number of cesarean deliveries, particularly of nulliparous women, after induction. For instance, the indications for cesarean delivery in those studies have not been evaluated. However, these observations suggest that transvaginal measurement of cervical length may be an even better predictor of successful induction and fewer cesarean deliveries.

Differences in the use of induction agents may have an impact on the induction-to-delivery interval but probably not on the rate of vaginal delivery. However, since the optimal dosage of PGE2 vary among the individual women, these is certainly associated with the frequency and value of repeated PGE2 applications (Mackenzie and Burns 1997). Previous studies used the controlled - release PGE2 vaginal insert for labor induction, found that in normal vaginal $\mathrm{pH}$, vaginal PGE2 would be predominantly ionized and less available for absorption into the maternal circulation. They suggested that the high PGE2 release rate would not equate to increased plasma concentrations of PGE2 or its metabolites (Rayburn 1997, and Blair et al 1998). Hence, our results showed significantly higher serum PGE2 concentrations in women who had delivered vaginally than those who had delivery by cesarean section, inspite receiving nearly the same dosage. These women would therefore appear to be more responsive to $\mathrm{PGE} 2$ than those who had delivery by cesarean section. However, we could not use serum PGE2 concentrations as a routine for prediction of successful labor induction, as the analyses of prostaglandin metabolites are problematic because these metabolites rapidly disappear from the circulation. Furthermore, previously marketed kits for PGE2 analyses are no longer available, probably due to reproducibility and reliability problems as stated by Blair et al (1998).

Digital examination of the cervix is subjective and has considerable interobserver variability. Furthermore, only that portion of the cervix below the anterior vaginal wall is assessed (Phelps et al, 1995). Inspite, Bishop score is widely available and economical but has been poorly reproducible. Holcomb and Smeltzer (1991) reported that its sensitivity was low, and its positive predictive value was extremely low.

Some studies have suggested that interventions based on cervical scan may lead to improve outcomes. Ware et al (2000) found that cervical length was an independent predictor of mode of delivery, whereas the Bishop score was not. they suggested that if transvaginal ultrasonography did not lie as a superior method of assessing the cervix, there are other aspects of ultrasonography that may make this technique more useful than the Bishop score to the clinician: reproducibility, quantitation, and hard copy documentation.

Cervical ultrasound undoubtedly allows a far better assessment of the cervical ripening than clinical examination. Transvaginal approach yields clear and more detailed images due to both the close proximity of the 
ultrasound probe to the cervix and the higher transducer frequencies used. Furthermore, Cervical ultrasonography had the best prediction for the mode of delivery than digital examination.

We concluded that transvaginal ultrasonographic cervical measurement is comparable to Bishop score and serum PGE2 in assessing cervical ripeness for labor induction. Cervical measerments, parity and serum PGE2 were independent predictors of the mode of delivery. Whereas, the mode of delivery cold not be predicted in women with Bishop score $\leq 4$.

We suggested that cervical ultrasono -graphy is not well studied for use as a primary test of cervical ripening and both equipment and operator expertise is required. There may be other useful information, in addition to measurements of cervical length, which can be obtained from transvaginal ultrasound, detection of endocervical mucosal layer for assessment of cervical ripeness. Until then, the clinical utility of these tests remains unknown.

\section{REFERENCES}

Blair FC, Tassone SA, Pearman CR, and Rayburn WF: Inducing labor with a sustained release PGE2 vaginal insert. Experience at a community hospital. J Reprod Med 1998, 43: 408-12.

Boozarjomehri F, Timor-Tritsch I, Chao CR and Fox HE: Transvaginal ultrasonographic evaluation of the cervix before labor: presence of cervical- wedging is associated with shorter duration of induced labor. Am J Obstet Gynecol 1994; 171:1081-7.

Ellwood DA, Mitchell MD and Anderson ABM: The in vetro production of prostanoides by the human cervix during pregnancy prelimenary odservations. Br J. Obstet Gynecol. 1981; 187: 210- 14.
Gonen R, Degani S and Ron A: Prediction of successful induction of Labor: comparison of transvaginal ultrasonography and the Bishop score. Eur J Ultrasound 1998; 7:183-7.

Holcomb WL and Smeltzer JS: Cervical effacement: Variation in believe among clinitians. Obestet Gynecol 1991;78: 43-5.

Iams ID. Goldenberg R1.. Meis PJ, Mercer KM. Moawad A and Das A: The length of the cervix and the risk of spontaneous premature delivery. National Institute of Child Health andHuman Development MaternalFetal Medicine Units Network. N Engl J Med 1996; 334: 567-72.

Khoury S. Odeh M, Korshonov M, Wolfson $M$ and Oettinger $M$ : Transvaginal evaluation of the cervix before induction of labor. In: Proceedings of the Eighth World Congressof Ultrasound in Obstetrics and Gynecology; 1997: Washington, DC. Washington: The Congress: 1997.

Mackenze I and Balond J: Current theraputic use of prostaglandins in obstetrics in the United Kingdom. Contemp Rev Obstet Gynecol; 1997; 5: 9-14.

Munoz H, Diaz G, Lecannelier D, Paderaza D, Said S and Jankelevich J: Ultrasound cervix evaluation in the prediction of successful labor induction .In: Proceedings of the Eighth World Congress of Ultrasound in Obstetrics and Gynecology; 1997; Washington, DC. Washington: The Congress; 1997.

Paterson-Brown S, Fisk NM. Edmonds DK and Rodeck $\mathrm{CH}$ : Preinduction cervical assessment by Bishop's score and transvaginal ultrasound. Eur $\mathbf{J}$ Obstet Gynecol Reprod Biol 1991; 40:17-23.

Phelps JY, Higby K, Smyth MH, Ward JA, Arredondo $F$ and Mayer AR: Accuracy and interobserver variability of simulated cervical dilatation 
measurments. Am J Obstet Gynecol 1995; 173:942-45.

Rayburn WF: Clinical experience with controled release prostaglandine E2 intravaginal insert in the USA.Br $\mathrm{J}$ Obstet Gynecol 1997; 104: 8-12.

Sanchey-Ramos I, Kaunitz AM, Wears RL, Delke Infection and Gaudier FLMisoprostol for cervical ripening and labor induction: a metaanalysis. Obstet Gynecol. 1997; 89:633-42.

Sekiya T, Ishihara K, Yoshimatsu K., Fukami T, Kikuchi $\mathrm{S}$ and Araki T: Detection rate of the cervical gland area during pregnancy by transvaginal sonography in the assessment of cervical maturation. Ultrasound Obstet Gynecol 1998; 8:95.

Ware V.and Raynor BD : Transvaginal ultrasonographic cervical measurement as a predictor of successful labor induction. Am J Obstet Gynecol. 2000; 182:1030-2.

Williams MC. Krammer J and O'Brien WF: The value of the cervical score- in predicting successful outcome of labor induction. Obstet Gynecol . 1997; 90:784-9.

Xenakis KM, Piper JM, Conway D L and Langer 0: Induction of labor in the nineties: conquering the unfavorable cervix. Obatet Gynecol. 1997 :90:235-9

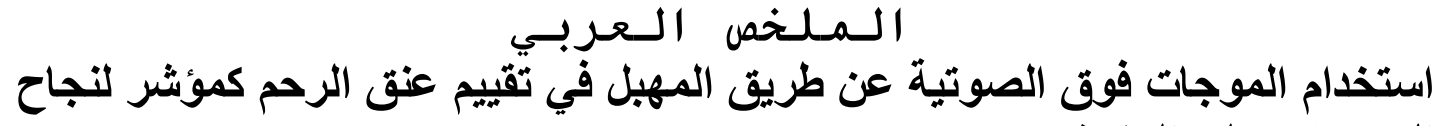

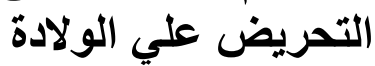 نَّاهد حسين محمد- نجلاء حسين محمد ـ محمود احمد منصور}

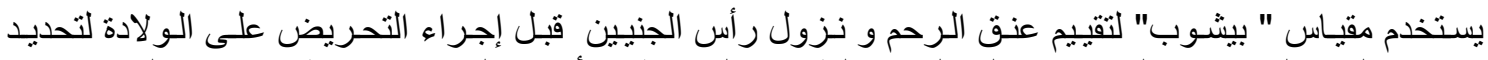

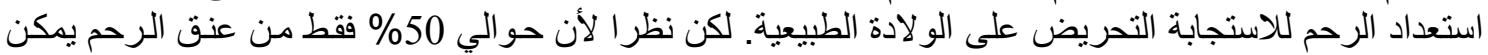

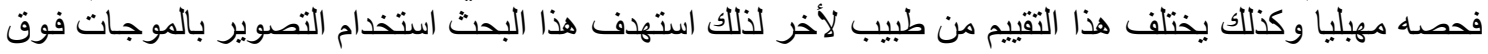

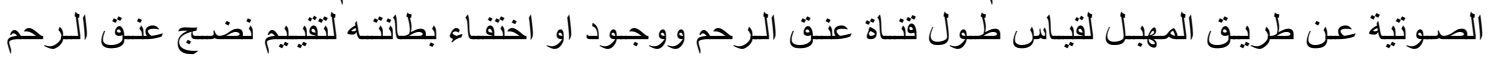

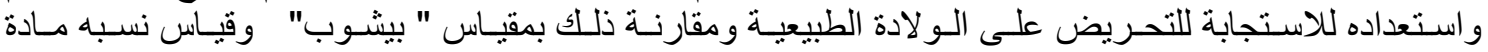

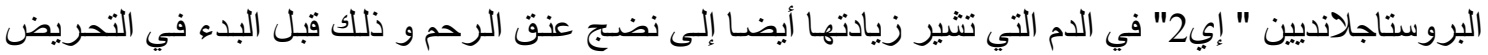

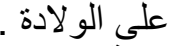

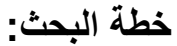

اشتمل البحث علي 80 سيدة حامل اكتملت مدة حملهن ( بعد إتمام الأسبوع 37) وكان مكان من الضروري إنهاء حملهن

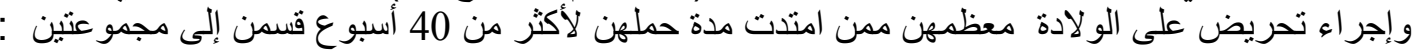

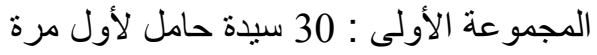

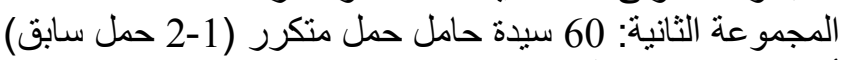
أجرى لكل سيدة الآتي:

1. التصوير بالموجات فوق الصوتية عن طريق المهبل لقياس طول قناة عنق الرحم ووجود أو اختفاء

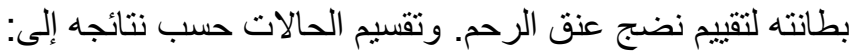

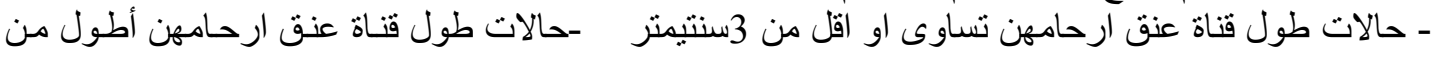
3

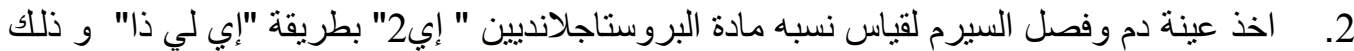

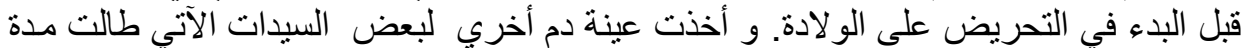

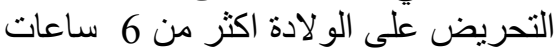

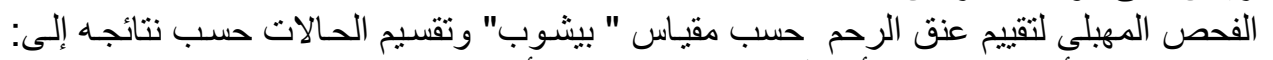
- - حالات قيمن و أخذن مقياس 4 أو اقل

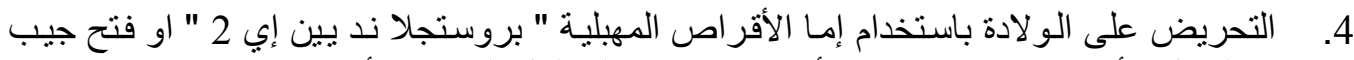

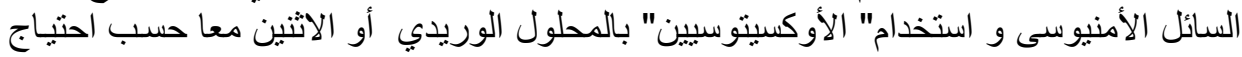


كل حالة.

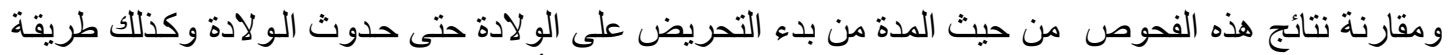

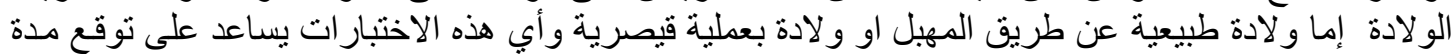

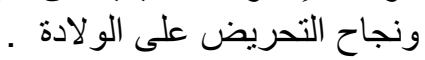

الاستنتاج :

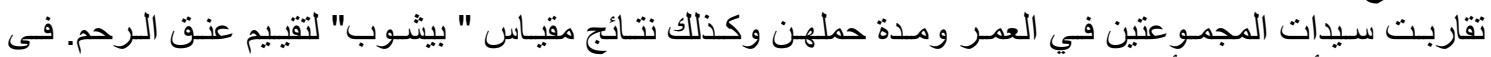

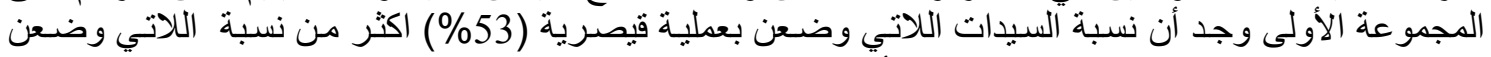

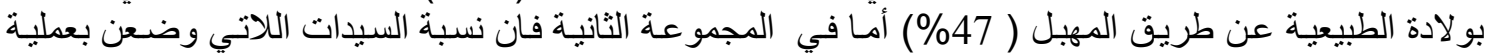

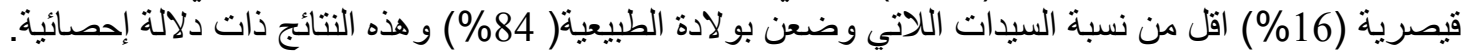

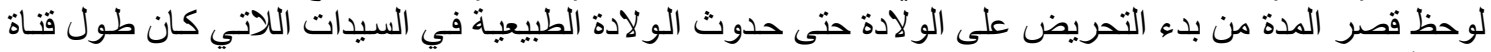

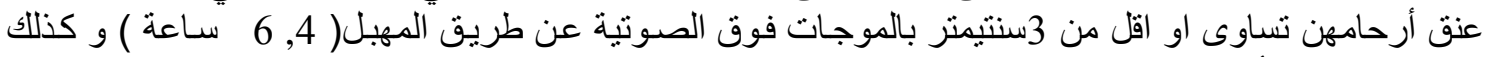

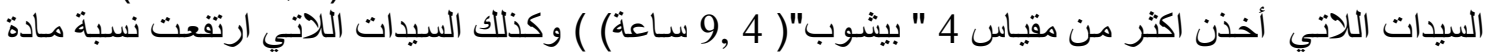

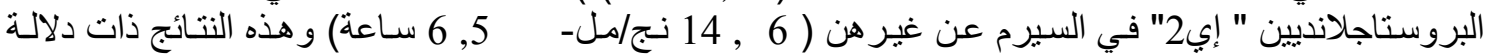

إحصائية.

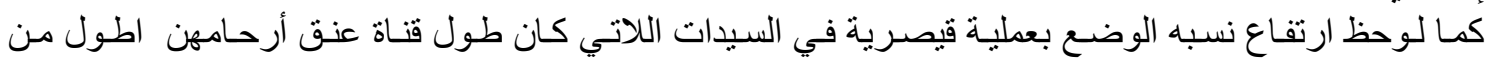

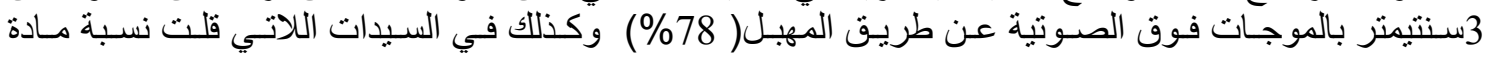

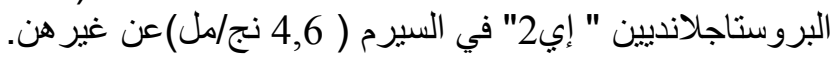

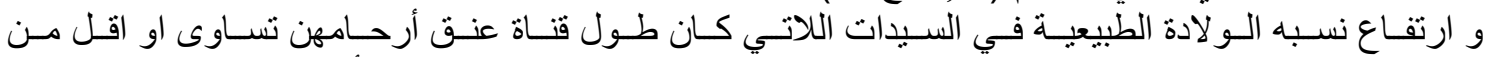

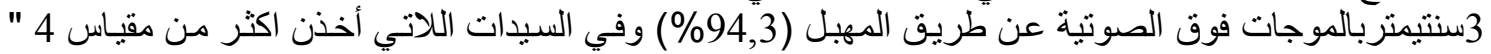

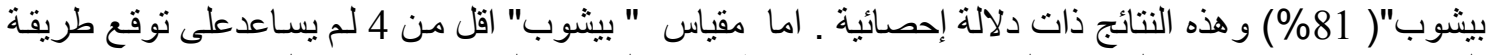

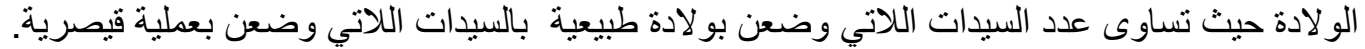

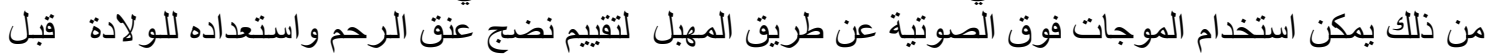

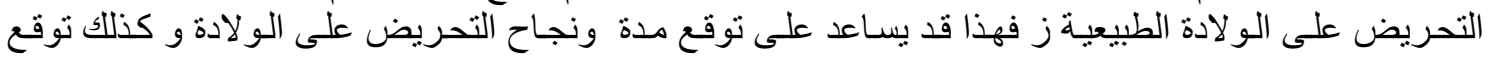
طريقة الو لادة اما ان تكون و لادة طبيعية او بعملية قيصرية. 